\title{
INFLUENCE OF ENVIRONMENTAL CONDITIONS ON PROPERTIES OF IONOMERIC AND RESIN SEALANT MATERIALS
}

\author{
Kamila Rosamilia KANTOVITZ ${ }^{1}$, Fernanda Miori PASCON${ }^{1}$, Gisele Maria CORRER ${ }^{2}$, Roberta Caroline Bruschi ALONSO ${ }^{3}$, \\ Lidiany Karla Azevedo RODRIGUES ${ }^{4}$, Marcelo Correa ALVES ${ }^{5}$, Regina Maria PUPPIN-RONTANI ${ }^{6}$
}

\author{
1- DDS, MSc, PhD Student of Pediatric Dentistry, Department of Pediatric Dentistry, Piracicaba Dental School, State University of Campinas, \\ Piracicaba, SP, Brazil. \\ 2- DDS, MSc, PhD, Full Professor, Dentistry Graduate Program, Positivo University, Curitiba, PR, Brazil. \\ 3- DDS, MSc, PhD, Collaborator Professor of Dental Materials, Department of Restorative Dentistry, Piracicaba Dental School, State University of \\ Campinas, Piracicaba, SP, Brazil. \\ 4- DDS, MSc, PhD, Professor of Operative Dentistry, Department of Operative Dentistry, Dentistry and Nursing, Federal University of Ceará, Fortaleza, \\ CE, Brazil. \\ 5- DDS, MSc, PhD, Student of Anatomy, Department of Morphology, Piracicaba Dental School, State University of Campinas, Piracicaba, SP, Brazil. \\ 6- DDS, MSc, PhD, Full Professor, Department of Pediatric Dentistry, Piracicaba Dental School, State University of Campinas, Piracicaba, SP, Brazil.
}

Corresponding address: Profa. Dra. Regina Maria Puppin-Rontani, Área Odontopediatria, Departamento de Odontopediatria, Faculdade de Odontologia de Piracicaba, UNICAMP - Av. Limeira, 901- Piracicaba - SP - Brasil - 13414-900 - Phone: +55-19-2106-5286 - Fax: +55-19-2106-5218 - e-mail: rmpuppin@fop.unicamp.br

Received: June 6, 2008 - Accepted: October 9, 2008

\begin{abstract}
$O$

bjectives: The aim of this study was to determine the effect of environmental conditions on the degradation of ionomeric and resin sealant materials. Material and Methods: FluroShield, Vitremer, and Ketac Molar disc-shaped specimens ( $\mathrm{n}=18 / \mathrm{material})$ were prepared, polished, subjected to initial hardness and roughness readings. Six discs of each material were randomly assigned to one of three different storage solutions: $0.3 \%$ citric acid (CA), demineralization solution (DE), and remineralization solution (RE). The specimens were individually immersed in $3 \mathrm{~mL}$ of the test solutions, which were daily changed. After 15 days of storage, new surface roughness and hardness readings were done. Fluoride release in the solutions was measured within 15 days. Data were analyzed by ANOVA and Tukey's and Contrast tests $(\alpha=0.05)$. Results: The storage in CA increased the roughness of Vitremer and Ketac Molar. A significant reduction in hardness was observed for all materials after storage in all solutions. For all materials, the greatest amounts of fluoride release occurred during the $1^{\text {st }}$ day. FluroShield presented the same patterns of fluoride release in all solutions. Ketac Molar and Vitremer released the highest amounts of fluoride in the CA solution. Conclusions: Ionomeric materials are more susceptible to degradation than resin-based materials under acidic conditions. Acidic conditions lead to a higher fluoride release from ionomeric materials.
\end{abstract}

Key words: Environmental biodegradation. Fissure sealant. Fluoride. Hardness. Roughness.

\section{INTRODUCTION}

Sealants have been developed to protect pits and fissures from caries by acting as a physical barrier to protect vulnerable areas. The introduction of fluoride-releasing sealants has widen the perspectives in the prevention of pit and fissure caries ${ }^{21}$. Fluoride-releasing materials can provide benefits in areas near to the sealant margins where the acid challenge may result in enamel demineralization ${ }^{10}$. In addition, the anticariogenic effect of fluoride-releasing fissure sealants depends on the amount of released fluoride, but obviously even more on the longevity of this release ${ }^{5}$.

In addition to traditional fluoride-releasing resin sealants ${ }^{13}$, other fluoride-releasing materials have been used as fissure sealants, such as conventional glass ionomer cements $(\mathrm{GICs})^{10}$ and resin-modified GICs (RMGICs) ${ }^{13}$. These materials should provide constant fluoride release for a prolonged period of time and act as a reservoir of fluoride ion in order to promote fluorapatite formation in enamel ${ }^{9}$.

Another factor in the clinical performance of sealant materials is related to biodegradation in the oral environment. The chemical degradation depends on the solution and material. It can be caused by acid challenges, including those produced by the cariogenic biofilm ${ }^{6}$, acidic $\operatorname{diet}^{25}$ and salivary enzymes ${ }^{6}$. Each type of solution will mainly degrade components of the resin-based material. 
According to Yap, et al. ${ }^{25}$ (2000), BisGMA matrix is susceptible to the softening effect of the food simulating liquids. Moreover, the inorganic filler may be damaged by water and weak intraoral acids, such as citric and lactic $\operatorname{acids}^{25}$. GICs have also been shown to interact with various storage media. In saliva they undergo a surface reaction that leads to the precipitation of calcium and phosphate ions at the outermost layer ${ }^{17}$. In acid conditions, matrix-forming ions are found to be released into the solution, as part of a process of buffering the medium ${ }^{3}$. In addition, the nature of the resin matrix, size, type, and distribution of filler particles regulate the biodegradation of ionomeric and resin-based materials ${ }^{25}$.

The effects of chemical degradation are surface softening and roughening, which can decrease the long-term durability of the sealer material ${ }^{25}$. As a consequence, degraded sealants could encourage dental biofilm accumulation, which may result in superficial staining and onset of caries lesions, reducing the physical properties of the material ${ }^{2}$.

Although fluoride release has been the subject of numerous in vitro studies, the roughness and hardness pattern of fluoride-releasing materials in different storage media should be accessed. The purpose of this study was to determine the effect of acidic solutions on the degradation of ionomeric and sealant materials by means of hardness, roughness and fluoride release measurements. The first hypothesis tested was that GICs show greater degradation than resin sealant materials when stored in different solutions. The second hypothesis was that storage in acidic solution leads to higher fluoride release from the tested materials.

\section{MATERIAL AND METHODS}

\section{Experimental Design}

Three materials were used in this in vitro experiment: a resin fissure sealant (FluroShield), a RMGIC (Vitremer) and a conventional GIC (Ketac Molar). The brand names, types, compositions, manufacturers and batch numbers of the tested materias are presented in Figure 1. Eighteen disc-shaped specimens of each material were prepared and had their initial roughness and hardness determined for baseline information. Next, 6 discs of each material were randomly selected by lottery method and assigned to one of three different storage solutions: $0.3 \%$ citric acid solution (CA); demineralizing solution (DE); and remineralizing solution (RE; artificial saliva). The solutions were changed daily during the experimental period of 15 days. Fluoride concentration in the solutions was also determined daily. New roughness and hardness readings of the materials were done at the end of the experimental period.

\section{Specimen Preparation}

Fifty-four disc-shaped specimens $(6 \mathrm{~mm}$ in diameter and $2 \mathrm{~mm}$ in thickness) were prepared according to the manufacturers' specifications, at room temperature $\left(23 \pm 1.0^{\circ} \mathrm{C}\right.$ and $50 \pm 5 \%$ relative humidity, ISO \#7489 specification). The materials were inserted in plastic molds in a single increment and pressed between polyester strip and glass plates. A piece of paraffin-coated dental floss was incorporated into the cements during setting to suspend the samples in the test solution. The resin-based materials FluroShield and Vitremer were light cured on both sides (surface and bottom) for $40 \mathrm{~s}$ using a light-curing unit (Elipar

\begin{tabular}{|c|c|c|c|}
\hline Material & Type & Composition & $\begin{array}{c}\text { Manufacturer and } \\
\text { batch number }\end{array}$ \\
\hline FluroShield & Resin fissure sealant & $\begin{array}{l}\text { Urethane modified Bis-GMA dimethacrylate; } \\
\text { Barium aluminoborosilicate glass (30\%), } \\
\text { Polymerizable dimethacrylate resin, Bis-GMA, } \\
\text { Sodium fluoride, Dipentaerythritol pentaacrylate } \\
\text { phosphate, Titanium dioxide, Amorphous silica. }\end{array}$ & $\begin{array}{l}\text { Dentsply DeTrey } \\
\text { Konstanz- Germany } \\
\text { \# } 317131\end{array}$ \\
\hline Vitremer & $\begin{array}{l}\text { Resin-Modified glass- } \\
\text { ionomer cement }\end{array}$ & $\begin{array}{l}\text { Powder. fluoraluminosilicate glass, redox catalyst } \\
\text { system, pigments } \\
\text { Liquid: aqueous solution of a polycarboxylic acid } \\
\text { modified with pedant methacrylate groups, } \\
\text { Vitrebond copolymer, water, HEMA, } \\
\text { photoinitiators. } \\
\text { Primer. Vitrebond copolymer, HEMA, ethanol, } \\
\text { photoinitiators. }\end{array}$ & $\begin{array}{l}\text { 3M/ESPE, } \\
\text { St. Paul, MN USA } \\
\text { \# } 20020612\end{array}$ \\
\hline Ketac Molar & Glass Ionomer & $\begin{array}{l}\text { Powder: Aluminum-calcium-lanthanum- } \\
\text { fluorosilicate glass, } 5 \% \text { polycarbonate acid } \\
\text { Liquid: Polycarbonic acid and tartaric acid }\end{array}$ & $\begin{array}{l}\text { 3M/ESPE, St. Paul, } \\
\text { MN USA } \\
\text { \# } 159323\end{array}$ \\
\hline
\end{tabular}

FIGURE 1- Brands, compositions, manufacturers and batch numbers of the materials used in the study 
Tri-light; ESPE, Seefeld, Germany). Light output was periodically checked $\left(580 \pm 30 \mathrm{~mW} / \mathrm{cm}^{2}\right)$ with a curing radiometer (Model 100, Demetron Research Corp., Danbury, CT, USA). The conventional GIC, Ketac Molar, was allowed to set under pressure for $10 \mathrm{~min}$.

After setting, all surfaces of the discs, except the surface under the polyester matrix, were protected with an acidresistant nail polish (Colorama, São Paulo, SP, Brazil). All discs were stored for $24 \mathrm{~h}$ at $37^{\circ} \mathrm{C}$ and $100 \%$ humidity, and polished with 600- and 1200-grit $\mathrm{Al}_{2} \mathrm{O}_{3}$ paper (Arotec S.A. Ind. and Com., São Paulo, SP, Brazil) and then cloth polished with 1.0-mm diamond paste (Buheler Metadi II; Buheler, Lake Buff, IL, USA) before starting the experimental phase.

\section{Experimental Phase}

\section{Surface Roughness Test}

Each specimen was gently dabbed dry with absorbent paper and the surface roughness was analyzed with a surface roughness-measuring instrument (Surfcorder SE1700; Kosaka Corp, Tokyo, Japan) equipped with a diamond needle of $2-\mu \mathrm{m}$ radius. In order to record roughness measurements, the needle was moved at a constant speed of $0.5 \mathrm{~mm} / \mathrm{s}$ under a $0.7 \mathrm{mN}$ load. The cut-off value was set at $0.25 \mathrm{~mm}$ to maximize filtration of surface waviness. The surface roughness was characterized by the average roughness $(\mathrm{Ra})$, which is the arithmetical average value of all absolute distances of the roughness profile from the centerline within the measuring length. Ra values for each specimen were taken across the diameter over a standard length of $0.25 \mathrm{~mm}$. Three traces were recorded for each specimen at three different locations - parallel, perpendicular, and oblique to scan all specimen area. The average of these three traces was used as the score for each specimen. The roughness test was performed at baseline (B) and after 15 days $(\mathrm{F})$, and the delta roughness $(\Delta \mathrm{R})$ was determined using the following equation: $\Delta R=\frac{F}{B} \times 100$

\section{Knoop Hardness test}

Knoop Hardness measurements were obtained on the exposed surface using a microhardness tester (HMV-2000, Shimadzu, Japan) with a Knoop diamond under a $50 \mathrm{~g}$ load for $10 \mathrm{~s}$. The measurement of the indentation was performed immediately after the period of $10 \mathrm{~s}$. Three indentations spaced $1 \mathrm{~mm}$ from each other were made in the central area of each specimen. The hardness test was performed at baseline (B) and after 15 days $(\mathrm{F})$, and the delta hardness $(\Delta \mathrm{H})$ was determined using the following equation: $\Delta H=\frac{F}{B} \times 100$

\section{Fluoride Analysis of the Storage Media}

After baseline hardness and roughness tests, all specimens were individually immersed in $3.0 \mathrm{~mL}$ of each solution. The storage media used were: $0.3 \%$ citric acid solution (pH 3.2); DE solution (2.0 mM calcium, $2.0 \mathrm{mM}$ phosphate and acetate buffer $75 \mathrm{mM}, \mathrm{pH} 4.3$ ); and $\mathrm{RE}$ solution (artificial saliva composed of $1.5 \mathrm{mM}$ calcium, 0.9 $\mathrm{mM}$ phosphate, $\mathrm{KCl} 150 \mathrm{mM}$ and Tris [tris- (hydroxymethyl) aminomethane] buffer $20 \mathrm{mM}$, pH 7.0). The tubes were kept under constant agitation at $120 \mathrm{rpm}, 1.7 \mathrm{~Hz}$ (Cientec Model
CT 165, Piracicaba, SP, Brazil) at controlled temperature of $25 \pm 1.0^{\circ} \mathrm{C}$. The storage media were changed every $24 \mathrm{~h}$.

Duplicate aliquots of the solutions were mixed with TISAB III at a ratio of 1:0.1 and analyzed using an ionselective electrode (Orion 96-09; Orion Research Inc., Boston, MA, USA) and a digital ion-analyzer (Orion EA940; Orion Research Inc.), which was previously calibrated with various standard solutions $(0.065,0.125,0.250,0.500$, and $1.000 \mathrm{mg}$ of $\mathrm{F} / \mathrm{mL}$ ). The results obtained from each sample at 1, 2, 3, 5, 7, 9, 12, 15 days were analyzed and the result was divided by the specimen area (exposed area $=$ $28.26 \mathrm{~mm}^{2}$ ). The amount of released fluoride in the different time periods was evaluated.

\section{Statistical Analysis}

Original data for roughness, hardness and fluoride release were transformed $(\log 10, \log 10$, and 0.3 exponential, respectively) before applying ANOVA, repeated-measures ANOVA and Tukey's and contrast tests, since variance was not homogeneous. A multi-factor ANOVA was applied to the roughness and hardness data to analyze the interactions between the factors (materials and degradation solution). In order to assess significant differences within these factors, Tukey's test was applied.

For fluoride release data, the repeated-measures ANOVA was applied to verify the interaction of the materials, degradation solution, and fluoride release day of evaluation. Tukey's test was used to assess significant differences among these factors. In addition, the contrast test was performed to verify the differences among the 1 st day of fluoride release and the release at days 2, 3, 5, 7, 9, 12 and 15. The SAS statistical software (version 8.02, SAS Institute Inc., Cary, $\mathrm{NC}$, USA) was used and the significance level was set at $5 \%$.

\section{RESULTS}

The percentage of the increases and standard deviation of surface roughness $(\Delta \mathrm{R})$ for comparisons among the materials and degradation solutions are shown in Figure 2. In addition, the original data of roughness mean $(R a-\mu \mathrm{m})$ and standard deviation (SD) before (baseline measurement - gray columns) and after storage are demonstrated in Table 1. The immersion in CA caused a greater increase in roughness for Vitremer and Ketac Molar than for FluroShield. RE and DE solutions caused a similar increase in roughness for all materials.

Table 2 shows the mean values and standard deviation of hardness before and after the storage. Before the storage (baseline measurement - gray columns), Ketac Molar was significantly harder than FluroShield. Vitremer showed intermediated hardness values, not differing from the other materials, regardless storage media. A significant decrease in hardness was observed for all materials in all solutions, there was no difference among the groups, considering the $\Delta \mathrm{H}$. After the storage in CA and DE, there was no difference among the materials. The storage in RE changed the ranking 


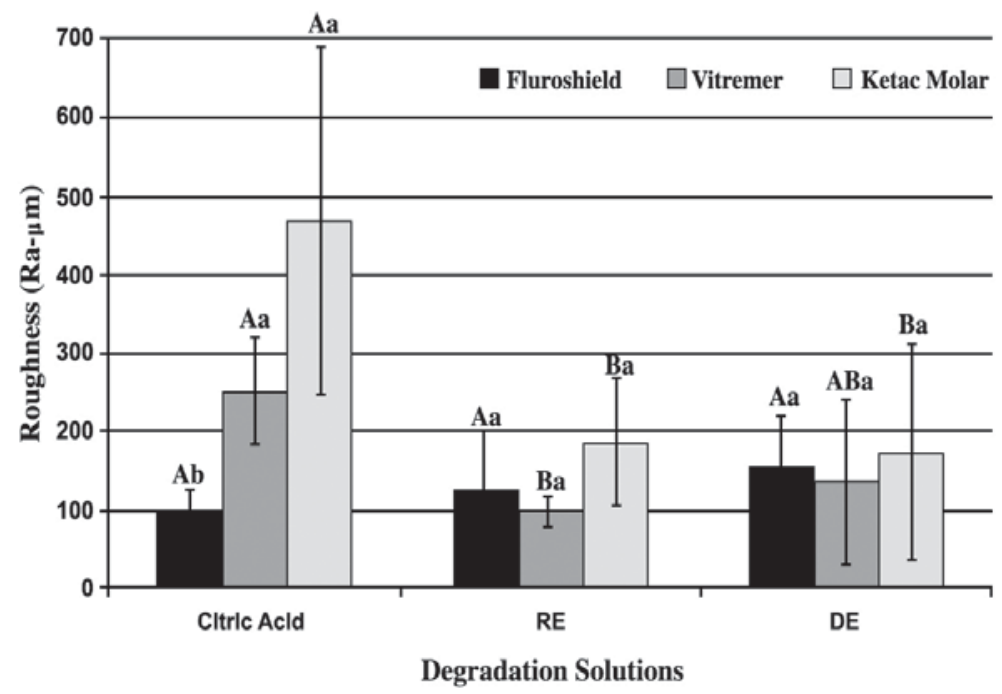

FIGURE 2- Percentage of roughness increase $(\Delta \mathrm{R})$ and standard deviation for comparisons among materials and degradation solutions. Same uppercase letters for the same material indicate no statistically significant differences among solutions, according to ANOVA and Tukey's test. ( $p>0.05)$. Same lowercase letters for the same solution indicate no statistically significant differences among materials, according to ANOVA and Tukey's test ( $p>0.05)$.

TABLE 1- Original data of roughness mean $(\mathrm{Ra}-\mu \mathrm{m})$ and standard deviation (SD) before and after storage

\begin{tabular}{lllllll}
\hline & \multicolumn{2}{c}{ FluroShield } & \multicolumn{2}{c}{ Vitremer } & \multicolumn{2}{c}{ Ketac Molar } \\
& Before & After & Before & After & Before & After \\
\hline & & & & & & \\
CA & $0.15(0.02)$ & $0.15(0.02)$ & $0.48(0.05)$ & $1.20(0.25)$ & $0.70(024)$ & $2.98(0.78)$ \\
RE & $0.18(0.05)$ & $0.20(0.08)$ & $0.49(0.10)$ & $0.47(0.10)$ & $0.68(0.16)$ & $1.19(0.44)$ \\
DE & $0.12(0.02)$ & $0.19(0.12)$ & $0.57(0.19)$ & $0.65(0.34)$ & $0.56(0.25)$ & $0.78(0.37)$ \\
\hline
\end{tabular}

TABLE 2- Original data of hardness mean (KHN) and standard deviation (SD) before and after storage

\begin{tabular}{|c|c|c|c|c|c|c|}
\hline & \multicolumn{2}{|c|}{ FluroShield } & \multicolumn{2}{|c|}{ Vitremer } & \multicolumn{2}{|c|}{ Ketac Molar } \\
\hline & Before & After & Before & After & Before & After \\
\hline $\mathrm{CA}$ & $25.60(2.18) A b^{*}$ & $2.22(0.43) \mathrm{Aa}^{*}$ & 34.97(3.61)Aab* & $4.22(1.01) \mathrm{Ba}^{*}$ & 38.20(8.93)Aa* & $4.28(0.53) \mathrm{Ba}^{*}$ \\
\hline RE & $25.43(1.71) A b^{*}$ & $5.57(1.92) A b^{*}$ & 33.27(3.77)Aab* & $9.35(3.18) \mathrm{Aa}^{*}$ & 39.1(10.14)Aa* & $9.68(3.54) \mathrm{Aa}^{*}$ \\
\hline $\mathrm{DE}$ & $26.37(3.24) A b^{*}$ & 3.05(1.29) $\mathrm{Aa}^{*}$ & $35.67(5.93) A a b^{*}$ & $3.78(1.39) \mathrm{Ba}^{*}$ & $38.43(4.96) \mathrm{Aa}^{*}$ & $6.02(1.73) \mathrm{Aba}^{*}$ \\
\hline
\end{tabular}

Similar capital letters in a column signify no significant statistical difference among solutions, according to ANOVA and Tukey tests $(p>0.05)$. Similar small letters in a line signify no significant statistical difference among materials, according to ANOVA and Tukey tests $(p>0.05)$, considering the same column colors. * Mean significant statistical difference between before and after storage.

of the materials as follows: Ketac Molar $=$ Vitremer $>$ FluroShield.

The patterns of fluoride ion release for the materials in different solutions are shown in Figure 3. All materials demonstrated higher fluoride release on the first day. Over the next days, the fluoride release decreased until it reached a plateau, in which the fluoride release was lower and constant until the end of the experiment (15 days). There was no difference in fluoride release for all materials in RE solution during the 15 days of the experiment ( $p>0.05)$. In the DE solution, on the 1st day, the fluoride release was ranked: Vitremer > Ketac Molar > FluroShield. After 3 days, fluoride release of all materials was similar. In the CA solution, during the first 2 days, Vitremer released the highest 

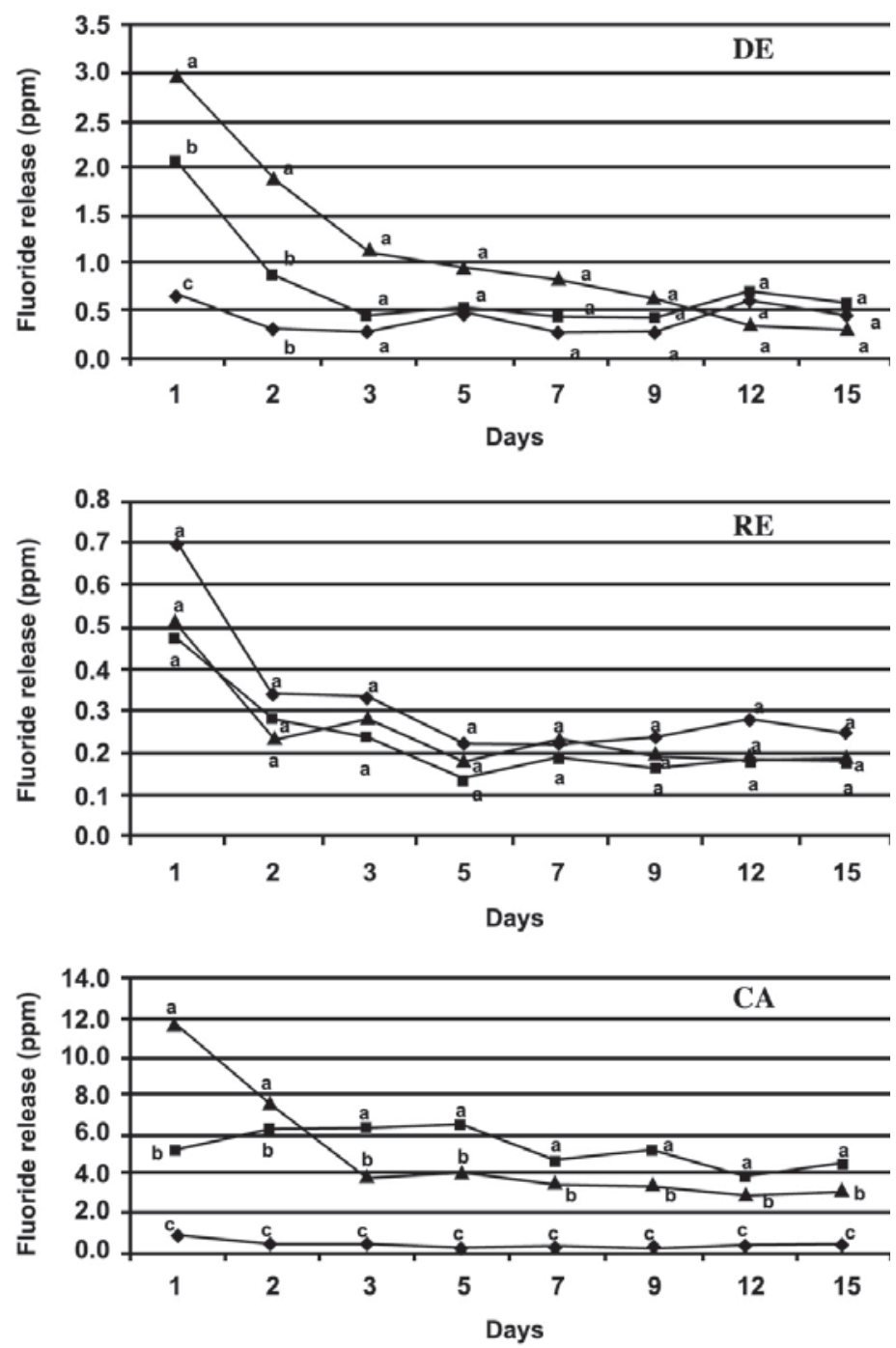

$\multimap$ Fluroshield $\longrightarrow$ Ketac Molar $\quad \longleftarrow$ Vitremer

FIGURE 3- Fluoride release from FluroShield, Ketac Molar and Vitremer in demineralization (DE), remineralization (RE), and citric acid (CA) solutions from day 1 to 15. Same uppercase letters for the same material indicate no statistically significant differences among solutions, according to ANOVA and Tukey's test ( $p>0.05)$.

amounts of fluoride, whereas after 3-15 days the release was highest for Ketac Molar.

FluroShield released the lowest amount of fluoride, and the pattern of fluoride released was the same in all solutions ( $>0.05$ ). Ketac Molar and Vitremer released the highest amounts of fluoride in CA solution $(\mathrm{p}<0.05)$. However, in this solution, these materials showed different fluoride release patterns. Ketac Molar showed a quite constant release, whereas Vitremer showed a significantly higher fluoride release on the first 2 days. For the other solutions (DE and RE), a similar fluoride release pattern was observed.

\section{DISCUSSION}

The effects of solutions that simulate the chemical oral environment on the surface roughness, hardness and fluoride ion release were investigated in this study. With regard to the hypotheses tested in this study, the first hypothesis that ionomeric sealant is more degraded by storage in different solutions than resin-based sealants was accepted. The increase in roughness was more accentuated in the GICs; however the reduction in hardness was similar for all materials.

The higher degradation of ionomeric materials by the citric acid solution can be explained by the characteristics of this acid: low $\mathrm{pH}$, higher concentration, titrability, and buffer capacity, as well as by the characteristics of the ionomeric 
materials. The main effect of citric acid on ionomeric materials seems to rely on the dissolution/disintegration of the glass particles ${ }^{14}$. Moreover, citric acid is a carboxylic acid capable of chelating ions present in the cement and forming complexes of reasonable solubility in water ${ }^{14}$. The influence of citric acid on the surface texture of Ketac Molar has been demonstrated by previous data ${ }^{15}$. This material was deteriorated when stored in low $\mathrm{pH}$ solutions, which makes it more susceptible to clinical failure ${ }^{15}$.

The acidic storage solution had no effect on the roughness of FluroShield. The absence of increase in roughness for FluroShield, after exposure to the storage solutions, is explained by the relationship between resin matrix and filler particles. This material presents silanized filler particles in a smaller size and content compared to GICs. Based on the effect of the storage solution on the degradation of the materials, it could be assumed that the acidic condition has a major effect on roughness due to the ionic dissolution of the filler particles.

The decrease in hardness of FluroShield seems to be related to the water sorption and hydrolysis, since all solutions, regardless of their $\mathrm{pH}$, had a similar effect on material hardness. The presence of water has a key role in the deterioration of resin-based materials. It may be suggested that the main effect of the solutions on resin-based materials is the swelling of the matrix caused by hydrolysis. According to Örtengren, et al. ${ }^{18}$ (2001), matrix swelling causes the formation of pores inside the material from which organic substances can be released, resulting in mass loss. The diffusion of water into the material may also lead to filler degradation and debonding.

The water sorption process is dependent on the hydrophilicity of the polymer matrix and on the presence and location of hydrolysable groups on the matrix chains ${ }^{8}$. The matrix of FluroShield is composed basically of BisGMA and TEGDMA, which are are hydrophilic monomers. The reduction in hardness may also affect the leaching of residual monomers into the solutions, especially TEGDMA ${ }^{7}$. In the RMGIC, a similar pattern of water sorption/degradation is expected. The elution of organic compounds such as BisGMA, UDMA, TEGDMA, HEMA and additives could be related to the observed reduction in hardness after storage in all solutions ${ }^{23}$.

With regard to hardness, the differences among materials at baseline are mainly related to differences in their composition and microstructure ${ }^{24}$. According to Xie, et al. ${ }^{24}$ (2000), there is a relationship between Knoop Hardness Number (KHN) and GIC's microstructure. Ketac Molar presents a very dense surface texture, with tightly packed glass particles in the matrix. The presence of different sizes and shapes of the glass particles dispersed on the matrix is another reason for the higher hardness ${ }^{24}$.

The marked reduction in hardness observed in Ketac Molar could be the result of a pronounced erosion of the polyacid matrix, the leaching of inorganic components, and an increased hydrolytic degradation at the matrix-filler interface ${ }^{1}$. In addition, an increase has been observed in the leaching of inorganic components, such as fluoride, and a reduction of surface hardness in acidic conditions, corroborating the results of Behrend and Geurtsen ${ }^{1}$ (2001).

The Vitremer's ionomeric component is similar to that of Ketac Molar. The crosslinks of RMGICs are formed between two chains of the polyacid, often via a HEMA molecule. In this region, carboxylate groups may be too far apart to be cross-linked via calcium ions. Thus, the reaction of the carbon double bond may physically separate the chains sufficiently to minimize the ionic interactions, providing a greater hardening and stiffening of the matrix ${ }^{19}$. Considering the intermediate microstructure of this resin-based ionomeric material, intermediate values of hardness were expected. With respect to FluroShield, this material is a resin-based sealant with relatively low filler content (about 50\%). This is the main cause of the reduced hardness observed for this material. Furthermore, the resin matrix, composed basically of BisGMA and TEGDMA, appears to be more resilient than the ionomeric matrix.

The second hypothesis tested in this study that acidic solutions lead to a higher fluoride release, was partially accepted, because this assumption worked only for the ionomeric materials. The fluoride release rates and periods of sealer materials are clinically important in establishing the extent to which dental caries can be prevented. The common finding for all the evaluated materials was the similar pattern of fluoride release in the three storage media. The kinetic profile of fluoride release was characterized by a rapid initial increase (first $24 \mathrm{~h}$ ) and, within 15 days of storage, a plateau was reached; however the materials continued to release low fluoride rates until the end of the experiment. Other studies showed similar patterns of fluoride release from a variety of materials $^{3,11}$.

The burst effect was observed for all materials, but it was more pronounced for Vitremer, which is consistent with the results of the previous studies ${ }^{1,4}$. It is assumed that two processes contribute to the amount of fluoride released. The first is a relatively fast release from the surface and the second mechanism is a long-term diffusion from the bulk of the material through cement pores and cracks ${ }^{12}$.

The nature of the storage media influenced the fluoride release. Vitremer and Ketac Molar presented great amounts of fluoride in the acid media (DE and CA solutions), in accordance with other studies ${ }^{11,16}$. This phenomenon is caused by an accentuated erosion of the polysalt matrix of the glass ionomer and because of the dissolution of this material, which increases with low $\mathrm{pH}^{5}$. The pattern of fluoride ion release found in Vitremer suggested that its fluoride release mechanism was similar to that of Ketac Molar, although the process of elution of fluoride seemed to take longer, probably because of the resin matrix, which reduces the elution rate of the fluoride ions.

FluroShiled material was characterized by a low fluoride release rate, regardless of the storage solutions. These results may be explained by the characteristics of the resin sealant matrix, which is less hydrophilic than that of conventional and RMGICs, making fluoride release more difficult ${ }^{20}$ and slower after polymerization ${ }^{22}$. The low fluoride release of FluroShiled raises the question of whether this resin-based 
sealant has a significant preventive effect in high caries-risk patients.

The findings of this study suggest that the mechanical and chemical properties of the sealant materials could be influenced by acidic solutions. Although the levels of fluoride release from conventional and RMGICs in these solutions were higher, these materials were more susceptible to acidic degradation (increase in roughness) than the resin sealant, suggesting that the choice for the sealant material must be based on the characteristics of the material, such as mechanical properties, fluoride release, and long-term durability, as well as the caries risk/activity of the patient. Nevertheless, periodic evaluation must be carried out because degradation is expected for all materials placed in the oral environment.

\section{CONCLUSIONS}

Based on the results of this study, it may be concluded that: 1 . Under acidic conditions, the ionomeric materials were more susceptible to degradation (increase in roughness) than the resin fissure sealant; 2 . Acidic conditions led to higher fluoride release from the ionomeric materials. However, a higher degradation (increase in roughness and decrease in hardness) was also observed in this condition; 3 . The resin fissure sealant was not affected by the acidic environment and showed similar roughness and fluoride release after storage in all tested media.

\section{REFERENCES}

1- Behrend B, Geurtsen W. Long-term effects of four extraction media on the fluoride release from four polyacid-modified composite resins (compomers) and one resin-modified glass-ionomer cement. J Biomed Mater Res. 2001;58:631-7.

2- Bollen CML, Lambrechts P, Quirynen M. Comparison of surface roughness of oral hard materials to the threshold surface roughness for bacterial plaque retention: a review of the literature. Dent Mater 1997;13:258-69.

3- Czarnecka B, Limanowska-Shaw H, Nicholson JW. Buffering and release by a glass-ionomer cement under near-neutral and acidic conditions. Biomaterials. 2002;23:2783-8.

4- Dionysopoulos P, Kotsanos N, Pataridou A. Fluoride release and uptake by four new fluoride releasing restorative materials. J Oral Rehabil. 2003;30:866-72.

5- Forsten L. Fluoride release of glass ionomers in glass ionomer the next generation. In: Hunt P (Ed). Proceedings of the $2^{\text {nd }}$ International Symposium on Glass Ionomers; 1994; Philadelphia, PA. Philadelphia: International Dental Symposia, PC; 1994.

6- Gee AJ, Wendl SL, Werner A, Davidson CL. Influence of enzymes and plaque acids on in vitro wear of dental composites. Biomaterials. 1996; $17: 1327-32$.

7- Geurtsen W. Substances released from dental resin composites and glass ionomer cements. Eur J Oral Sci. 1998;106:687-95.

8- Göpferich A. Mechanisms of polymer degradation and erosion. Biomaterials. 1996;17:103-14.
9- Kadoma Y, Kojima K, Masuhara E. Studies on dental fluoride releasing polymers IV. Fluoridation of human enamel by fluoride containing sealant. Biomaterials. 1983;4:89-93.

10- Kantovitz KR, Pascon FM, Correr GM, Borges AFS, Uchoa MN, PuppinRontani RM. Inhibition of mineral loss at the enamel/sealant interface of fissures sealed with fluoride- and non-fluoride containing dental materials in vitro. Acta Odontol Scand. 2006;64:376-83.

11- Karantakis P, Helvatjoglou-Antoniades M, Theodoridou-Pahini S, Papadogiannis Y. Fluoride release from three glass ionomers, a compomer, and a composite resin in water, artificial saliva, and lactic acid. Oper Dent. 2000;25:20-5.

12- Kuhn AT, Wilson AD. The dissolution mechanisms of silicate and glass ionomer dental cements. Biomaterials. 1985;6:378-82.

13- Lobo MM, Pecharki GD, Tengan C, Silva DD, Tagliaferro EPS, Napimoga MH. Fluoride-releasing capacity and cariostatic effect provided by sealants. J Oral Sci. 2005;47:35-41.

14- McKenzie MA, Linden RWA, Nicholson JW. The physical properties of conventional and resin-modified glass-ionomer dental cements stored in saliva, proprietary acid beverages, saline and water. Biomaterials. 2003;24:4063-9.

15- Mohamed-Tahir MA, Yap AU. Effects of $\mathrm{pH}$ on the surface texture of glass ionomer based/containing restorative materials. Oper Dent. 2004;29:586-91.

16- Muller U, Kielbassa AM, Schulte-Mönting J, Hellwig E. Fluoride release from light-curing restorative materials. Am J Dent. 2000;13:301-4.

17- Okada K, Tosaki S, Hirota K, Hume WR. Surface hardness change of restorative filling materials storage in saliva. Dent Mater. 2001;17:34-9.

18- Örtengren U, Andersson F, Elgh U, Terselius B, Karlsson S. Influence of $\mathrm{pH}$ and storage time on the sorption and solubility behaviour of three composite resin materials. J Dent. 2001;29:35-41.

19- Peutzfeldt A, García-Godoy F, Asmussen E. Surface hardness and wear of glass ionomers and compomers. Am J Dent. 1997;10:15-7.

20- Preston AJ, Agalamanyi EA, Higham SM, Mair LH. The recharge of esthetic dental restorative materials with fluoride in vitro-two years' results. Dent Mater. 2003;19:32-7.

21- Ripa LW. Dental materials related to prevention - Fluoride incorporation into dental materials: Reaction paper. Adv Dent Res. 1991;5:56-9.

22- Rock WP, Foulkes EE, Perry H, Smith AJ. A comparative study of fluoride-releasing composite resin and glass ionomer materials used as fissure sealants. J Dent. 1996;24:275-80.

23- Rogalewicz R, Batko K, Voelkel A. Identification of organic extractables from commercial resin-modified glass-ionomers using HPLC-MS. J Environ Monit. 2006;8:750-8

24- Xie D, Brantley WA, Culbertson BM, Wang G. Mechanical properties and microstructures of glass-ionomer cements. Dent Mater. 2000;16:12938.

25- Yap AUJ, Low JS, Ong LFKL. Effect of food-simulating liquids on surface characteristics of composite and polyacid-modified composite restoratives. Oper Dent. 2000;25:170-6. 